\section{Mn related defect levels in germanium}

J. Lauwaert ${ }^{1}$, F. Moens ${ }^{1}$, S.H. Segers ${ }^{1}$, K. Opsomer ${ }^{2}$, E. Simoen $^{1,2}$, J. Vanhellemont ${ }^{1}$, P. Clauws ${ }^{1}$, F. Callens ${ }^{1}$ and H. Vrielinck ${ }^{1}$.

${ }^{1}$ Department of Solid State Sciences, Ghent University, Krijgslaan 281-S1, 9000 Gent, Belgium

${ }^{2}$ Imec, Kapeldreef 75, B-3001 Leuven, Belgium

1. Introduction. Mn doped germanium was studied almost 60 years ago by means of Hall effect [1] and photo conductivity [2] measurements. Based on the temperature dependence of the resistivity and carrier concentration, two levels, one at $0.37 \mathrm{eV}$ from the conduction band and one at $0.16 \mathrm{eV}$ from the valence band have been assigned to Mn impurities[1]. In agreement with the valence bond model and similar observations by counterdoping with donors for $\mathrm{Fe}, \mathrm{Co}$ and $\mathrm{Ni}$, these impurities have been assigned to double acceptors. Moreover, the presence of a double acceptor level was confirmed by the observation of the $\mathrm{Mn}^{2-}$ state with Electron Paramagnetic Resonance (EPR). [3] However it was also noted in the early studies that the presence of contamination with acceptor impurities may cast doubt on the charge transition assignment. Since the availability of Deep Level Transient Spectroscopy (DLTS), which is a more reliable technique to study deep levels in semiconductors, the electronic properties of most of the $3 \mathrm{~d}$ transition metals have already been studied with a higher energy resolution. Metal in-diffusion was successful to introduce $\mathrm{Cu}$ and Ni[4]. More recently the defect levels of $\mathrm{Ti}, \mathrm{Cr}, \mathrm{Fe}$ and $\mathrm{Co}$ have been identified with DLTS on metal-implanted Ge $[5,6]$. The present study reports on results obtained on Mn doped Ge.

2. Experimental conditions. The source material are single crystal germanium wafers, supplied by Umicore, with a shallow dopant concentration of $10^{14} \mathrm{~cm}^{-3} \mathrm{Ga}$ and $\mathrm{Sb}$ for $\mathrm{p}$ - and n-type, respectively. To introduce $\mathrm{Mn}$ impurities, $99.995 \%$ pure $\mathrm{Mn}$ was thermally evaporated on the Ge surface. Afterwards the specimens were placed in a resistive furnace under Ar atmosphere for 10 minutes at $700^{\circ} \mathrm{C}$. Finally, the residual $\mathrm{Mn}$ on the surface was removed by etching with a mixture of $\mathrm{HNO}_{3}$ and $\mathrm{HF}$ (3:1?). Schottky diodes for DLTS were prepared by evaporation of $\mathrm{Au}$ (n-type) or In (p-type) barriers immediately after etching. To identify the contamination introduced during the processing, Schottky diodes were also prepared on parts of the specimens outside the Mn covered areas. Schottky diodes on $\mathrm{n}-\mathrm{Ge}$ were also prepared by annealing the n-Ge:Mn samples (after indiffusion at $700^{\circ} \mathrm{C}$ ) to $400^{\circ} \mathrm{C}$ for $20 \mathrm{~min}$ in order to form a MnGe metallic alloy contact.

3. Results and discussion. Fig. 1 a shows the DLTS spectrum of n-Ge:Mn with a MnGe Schottky contact. A similar spectrum was recorded on the specimen with an Au-Schottky barrier. Conventional DLTS shows one electron trap (Mn-E1), while injection of minority carriers $\left(\mathrm{V}_{\mathrm{p}}>0\right)$ reveals two additional levels (Mn-H1 and $\left.\mathrm{Mn}-\mathrm{H} 2\right)$. Fig. $1 \mathrm{~b}$ shows the DLTS spectrum of p-type Ge, with presence of Mn-H1 and Mn-H2 only after Mn diffusion.
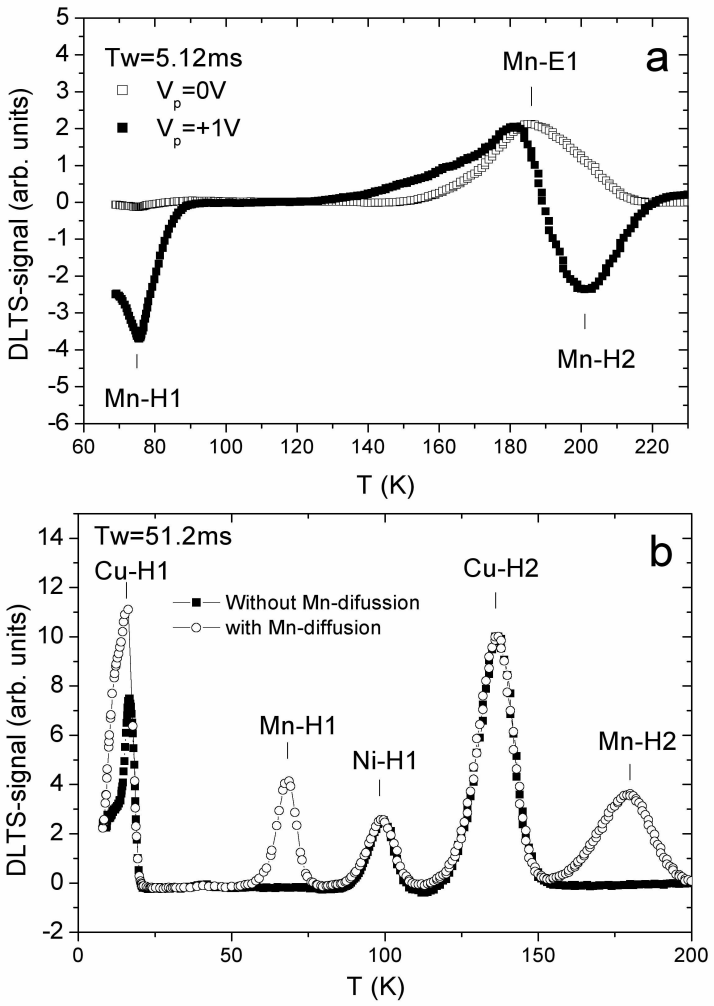

Figure 1: DLTS spectrum of a) $\mathrm{n}-\mathrm{Ge} / \mathrm{MnGe}$ diode. b) $\mathrm{p}$ type Ge with and without Mn-difussion.

The electron trap Mn-E1 $(\Delta \mathrm{E}=0.36 \mathrm{eV})$ and the hole trap Mn-H1 $(\Delta \mathrm{E}=0.14 \mathrm{eV})$ correspond with the two levels reported before $[1,2]$. The $\mathrm{Mn}-\mathrm{H} 2$ peak $(\Delta \mathrm{E}=0.34 \mathrm{eV})$ has to our knowledge not been reported before in the context of transition metal impurities. Nonetheless, its appearance only in Mn diffused samples, its almost equal amplitude and concentration profile to $\mathrm{Mn}-\mathrm{H} 1$ suggests that it is also related to substitutional $\mathrm{Mn}$ in Ge. This may indicate that the substitutional Mn defect can adopt 4 charge states in $\mathrm{Ge}$, one of which certainly corresponds with 2-, as identified with EPR.

4. Conclusions. Three Mn related defect levels have been identified with DLTS. The striking similarity with previously published results for two of the observed levels suggest the assignment to substitutional $\mathrm{Mn}$ in germanium. The third level was not reported before but can most probably also be assigned to Mn.

\section{References}

[1]H. H. Woodbury and W.W. Tyler, Phys. Rev., 100, p. 659 (1955).

[2]R. Newman, H.H. Woodbury and W.W. Tyler, Phys. Rev., 102, p. 613 (1956).

[3]G.D. Watkins, Bull. Am. Phys. Soc., 2, 235 (1957). [4]P. Clauws and E. Simoen Mater. Sci. Semicond. Process 9,546 (2006)

[5]J. Lauwaert, J. Van Gheluwe, J. Vanhellemont, E. Simoen and P. Clauws, J. Appl. Phys. 105, 073707 (2009)

[6]J. Lauwaert, J. Vanhellemont, E. Simoen, H. Vrielinck and P. Clauws, J. Appl. Phys. 111, 113713 (2012) 